\title{
A New Sticky Trap for Monitoring Seed Rain in Grasslands
}

\section{LAURA FOSTER HUENNEKE AND COURTNEY GRAHAM}

\section{Abstract}

The use of an inexpensive, commercially available device as a sticky trap for capturing dispersing seeds in the field is described. Trap performance in capturing seeds under various conditions is evaluated. The traps perform well in capturing small, lightweight seeds, particularly those with awns or ornamentation, as would be typical of many grassland plant species. The adhesive surface of the traps retains its effectiveness when moist, and in the hot, dusty conditions of the field. However, the traps have poor rates of capture for certain seed types, and for seeds dropped from considerable heights. These limitations of performance, which are probably shared with other types of sticky traps for seeds, must be considered when sticky traps are used to evaluate seed rain.

\section{Key Words: seed rain, seed traps}

Plant ecologists have long been interested in measuring seed rain (the composition and abundance of plant propagules arriving at a location) and seed shadow (the directions and distances travelled by seeds released from a parent plant). Incoming seeds represent an important component of the potential for recruitment to a population, or for regeneration of vegetation after a disturbance. The pattern of seed movements influences gene flow and the development of local genetic structure. Accurate measurements of seed rain and dispersal are thus crucial to many questions at both the population and community level.

A wide variety of methods has been used to trap seeds as they are dispersed in a plant community, but none is completely satisfactory. One technique is to take soil cores or samples at intervals through the year, to document changes in the number of germinable seeds in the soil seed bank through time. However, differences in germinable seed numbers between sampling dates may reflect changes in dormancy or seed status, as well as recent arrivals; seed germinability and variability may alter in a complex fashion during storage in the soil (Cook 1980).

Relatively large seeds, particularly those of woody species, are frequently caught in litter/seed traps constructed of mesh or screen. Sampling of small seeds in these traps is limited by mesh size. Seeds dispersing from a source may also be collected on sheets or tarps spread around the source. Post-dispersal seed predation (e.g., by rodents, ants, or birds) may affect the accuracy of seed counts in open traps. Seeds have also been trapped in vials or cups sunk into the soil, simulating natural depressions (Reichman 1984).

A common type of seed trap is the sticky trap, where a surface is coated with an adhesive and placed on or near the soil surface to collect small seeds. These traps have been used effectively in herbaceous communities such as grassland (e.g., Rabinowitz and Rapp 1980), but are sometimes cumbersome to work with and difficult to make uniform. In addition, the various adhesives used [including petroleum jelly (Verkaar et al. 1983) and sticky gum substances used to trap insects (Werner 1975)] almost certainly have different rates of effectiveness at trapping different types of seeds. To date, however, there have been no published measurements of the effectiveness of such traps with seeds of varying sizes, shapes, or dispersal modes.

In this note we describe a commercially available device which

\footnotetext{
The authors are of the Department of Biological Sciences, Stanford University, Stanford, California 94305 .

This research was supported by a grant from the Mellon Foundation to H.A. Mooney. W. Watt and C. Boggs generously allowed use of their tabletop wind tunnel. We thank B. Lilley for preparing the figure.

Manuscript accepted 14 May 1987.
}

serves admirably as a sticky trap for small seeds in many respects. The device is inexpensive, uniform, and available in bulk, making it suitable for intensive or extensive surveys of seed rain. We also test this trap's effectiveness in trapping various seeds of grassland species under conditions commonly encountered in the field.

\section{Methods}

\section{Sticky Traps}

We have used insulation hangers or mounts as sticky traps for small seeds. These hangers consist of squares of galvanized metal, 5 $\mathrm{cm}$ on a side, coated with a smooth surface of powerful adhesive, mounted on nails of various lengths. The nail allows the trap to be placed flush on the soil surface or mounted on wood dowels (or in glass or plastic tubing) at various heights above the ground. The squares are initially covered with a peel-off plastic sheet, which is removed when the trap is placed in the field. The hangers are available in bulk at hardware stores or through wholesale insulation suppliers (cost approximately 5-10 cents per hanger).

\section{Test of Trap Performance}

We tested the effectiveness of insulation hangers as sticky traps for seeds under conditions similar to those encountered in the field. The traps were $5 \mathrm{~cm}$ on a side, mounted on nails of $4 \mathrm{~cm}$ length. In most of the following trials, seeds were dropped vertically from a vial mounted on a ringstand onto the surfaces of fresh traps, in a room with minimal ventilation air currents. For most trials, seeds of tall fescue (Festuca elatior L., 'Kentucky 31'), a commercial lawn grass, were used because of their close similarlity to seeds of several California grassland species (including soft chess (Bromus mollis) L.; Italian rye (Lolium multiflorum Lam.); and a native annual fescue, Vulpia microstachys Munro ex Benth.) and their availability in bulk.

To test the effectiveness of the traps in capturing seeds released from various heights, seeds were dropped vertically in groups of 25 onto fresh traps (6 replicate traps per height). Twelve heights, ranging from $2-60 \mathrm{~cm}$ above the traps, were tested. We counted the numbers of seed which adhered to the trap surface.

Rain or dew might affect the ability of a sticky trap to capture seeds in field conditions. Festuca seeds were dropped in groups of 25 from a height of $10 \mathrm{~cm}$ onto fresh traps that had been thoroughly wetted with a mist sprayer. We first counted the numbers of seeds which remained on the trap surface; we then removed the trap and shook it vigorously to remove pooled droplets and any seeds which were not firmly adhered to the trap surface, and counted those remaining.

Some adhesives lose their stickiness when exposed to the high temperatures or light intensities often encountered in open grasslands, making them unsuitable for field use. Seed traps were placed flush with the soil surface in a California annual grassland of low productivity and short stature on a serpentine-derived soil. Traps were exposed for 5,13 , or 19 days and allowed to accumulate seeds, dust, insects, and other debris. Traps were then collected and stored in plastic bags in a cool, dry storage area until testing. Before testing we removed all seeds from the traps, but left dust and other debris in place. Trapping effectiveness was tested for 6 replicate traps of each age (including fresh traps, age 0 ) by dropping 6 groups of 25 Festuca seeds from $10 \mathrm{~cm}$ height (removing all captured seeds between groups).

Size, mass, and morphology of seeds may influence the rate at which they are trapped by a sticky surface. We tested the effectiveness of the seed traps at capturing seeds of 5 herbaceous species: the 
lawn grass Festuca elatior L.; the cultivated radish (Raphanus sativus L. (Cherry Belle)); and 3 species native to California grasslands, the annual forb Plantago erecta Morris and the perennial bunchgrasses Stipa pulchra Hitchc. and Sitanion jubatum J.G.Sm. In these trials 25 seeds of a species were dropped, 1 at a time, from $10 \mathrm{~cm}$ onto a fresh trap (6 replicate traps per species).

Arrays of seed traps were tested for their ability to trap seeds of 3 types carried by the airstream of a tabletop wind tunnel. Single seeds of Sitanion. Festuca, and Plantago were released at air velocity of $2.5 \mathrm{~m} / \mathrm{sec}$ and their behavior noted. Fifteen seeds per species (20 for Plantago)) were observed. Fresh seed traps were arranged side-by-side in such a way as to assure initial contact with dropping seeds.

After seeds have been captured by a sticky trap, they remain vulnerable to removal by wind (or by seed predators) as long as the trap remains in the field. We tested 6 traps that had collected full loads of seed in a California annual grassland by placing the traps in the airstream of a tabletop wind tunnel. Seed loads included seeds of a wide range of sizes and morphologies, including seeds with long or elaborated awns and seeds which seemed held only loosely by the adhesive surface of the trap. Traps were placed in the wind tunnel's airstream, and air velocity was varied from 0.1 to 3.0 $\mathrm{m} / \mathrm{sec}$.

\section{Results}

\section{Height of Release of Seeds}

Capture success was strongly influenced by the height from which seeds dropped onto the sticky traps (Fig. 1). The percentage

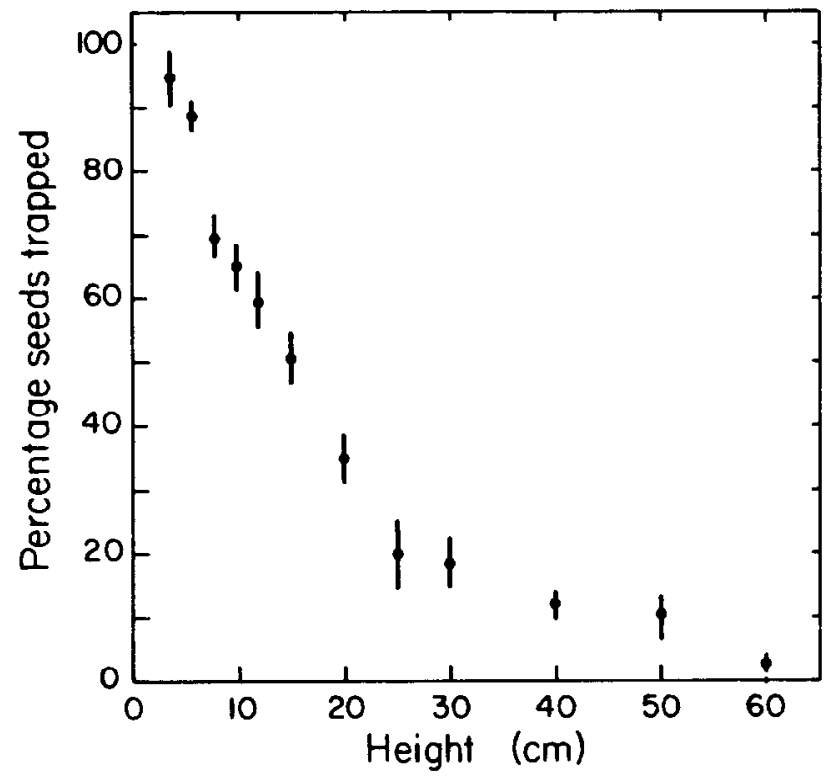

Fig. 1. Effect of height of seed release on the percentage of seeds trapped by the sticky traps. A group of 25 Festuca seeds was dropped from a vial vertically onto a clean dry trap. Means of 6 groups are plotted (bars represent \pm 1 standard deviation).

of seeds captured by the traps declined smoothly from $100 \%$ (height of release $2 \mathrm{~cm}$ ) to $3 \%$ (height of release $60 \mathrm{~cm}$ ). Seeds failing to adhere bounced off the trap surface after the vertical drop. The momentum gained by seeds in a vertical drop apparently makes capture on initial contact difficult. In a field situation, where air currents impart lateral as well as vertical velocity to seeds, some additional seeds would miss initial contact with a trap located directly below the point of release.

\section{Wetted Trap Surface}

Capture rates of wetted sticky traps were measured with seeds released from a height of $10 \mathrm{~cm}$ (about $65 \%$ capture success with dry traps). Surface wetting had no negative effect on the percentage of seeds trapped. In fact, wetted traps captured $92 \%(95 \%$ confidence interval, 89-94\%) of the seeds dropped; wetting actually increased initial capture rates, as the seeds adhered to the surface tension of the water droplets. When the traps were shaken to remove water droplets, $64 \%$ (95\% c.i., 58-69\%) of the seeds remained on the trap surface. The latter rate of retention did not differ significantly from that of dry traps $(t=0.2,31$ d.f.).

\section{Exposure to Field Conditions}

Exposure to light, high temperatures, and dust in the field had little influence on seed capture rates. Traps exposed for $0,5,13$, and 19 days had mean capture rates of $64,67,63$, and $67 \%$, respectively. Those traps exposed for 19 days, during a hot and dusty period of the summer, performed no differently than fresh traps ( $t=0.9,70$ d.f.).

\section{Comparison of Seed Types}

Trap effectiveness varied substantially with the size and morphology of seed (Table 1). Grass diaspores with long awns (Stipa and Sitanion) were caught with great efficiency. A grass caryopsis

Table 1. Comparison of sticky trap effectiveness at trapping seeds of various herbaceous species.!

\begin{tabular}{lcccc}
\hline \hline Species & $\begin{array}{c}\text { Mean } \\
\text { mass }\end{array}$ & Shape & $\begin{array}{c}\text { Awns } \\
\text { present? }\end{array}$ & trapped \\
\hline Stipa & $\mathrm{mg}$ & & & percentage \\
Sitanion & 9 & elongate & yes & $91(8)$ \\
Festuca & 17 & elongate & yes & $95(5)$ \\
Plantago & 2 & elongate & no & $56(6)$ \\
Raphanus & 15 & ovate & no & $15(6)$ \\
& 8 & round & no & $11(3)$ \\
\hline
\end{tabular}

ITwenty-five seeds of each species were dropped one at a time from a height of $10 \mathrm{~cm}$. Values represent means (standard deviations) for six traps tested per species.

with no awns (Festuca) was trapped at intermediate rates. In contrast, dense, smooth, rounded seeds (Plantago and Raphanus) tended to bounce off the trap without being trapped; fewer than $20 \%$ of those seeds were caught by the trap.

Seed type also influenced rate of capture in the wind tunnel tests. The long-awned diaspores of Sitanion attached themselves to the trap surface at the first point of contact in 14 of 15 cases. The 15 th bounced off the trap where it first hit and adhered to the second trap it contacted. The caryopses of Festuca became attached at the point of first contact in 4 of 15 cases, and adhered after a single bounce in 8 more cases. Three of the 15 seeds tested bounced repeatedly and failed to adhere to any trap. In contrast, none of the smooth dense Plantago seeds adhered at the point of first contact. Seven of 20 became attached to a trap surface after a single bounce, and 13/20 failed to adhere to any trap.

\section{Retention of Seeds in Windy Conditions}

Once caught on the trap surface, seeds could not be dislodged by exposure to the wind tunnel. Even when grass diaspores were attached only by long awns, no seeds were detached as wind speeds varied from 0.1 to $3.0 \mathrm{~m} / \mathrm{sec}$.

\section{Discussion}

These tests of performance demonstrate that inexpensive, commercially available insulation hangers may be used as effective traps for small seeds of some species under field conditions. The adhesive properties of the trap surface do not seem to be affected by the dust, high temperatures, or high light intensities encountered in open grassland sites. Wetting of the surface, as by dew or rain, did not diminish the effectiveness of the traps. In fact, the presence of water droplets seemed to increase the percentage of 
seeds remaining on the traps after initial contact. In the field, such seeds adhering to water droplets would likely become firmly attached to the adhesive surface when the water eventually evaporated. Unfortunately, variability in capture success rate with varying moisture conditions would make it difficult to extrapolate from trap captures to total seed rain.

The effectiveness of the traps is limited under certain conditions. Some seeds will not be retained by the traps, bouncing off after initial contact (particularly when falling from a considerable height, or when the seed is smooth and dense). The traps are effective at capturing seeds which are moving laterally, cither directly in a wind stream or after bouncing off other surfaces. Much of the movement of seed in the field, particularly in open vegetation such as grassland, is probably of this sort. This poor performance of the traps in retaining seeds dropped vertically from great heights would make them unsuitable for capturing seeds directly beneath a tall canopy. However, in grassland of low height, trap effectiveness would be adequate.

Substantial numbers of Plantago seeds, and other dense, smooth seeds, have been captured by these traps in the field despite the relatively poor capture efficiency for such seeds (Huenneke, pers. obs.). (Plantago erecta seeds do possess a wettable mucilage that, when moist, allows them to adhere tightly to the soil. However, during much of the seed dispersal season, conditions are dry and the seeds disperse with dry seed coats; the mucilage becomes wetted only later.) These numbers are almost certainly underestimates of the actual seed rain of such species. In contrast, propagules with long awns or hairs are caught very effectively by the traps, and numbers of seeds captured are probably good measurements of the rain of those species.

The performance limitations of these sticky traps may characterize sticky traps using other adhesives as well. The choice of a trap or adhesive must be an informed compromise between cost, performance under field conditions (moisture, dust, high light and temperatures) and effectiveness of capture of certain seed types. The availability of an inexpensive, uniform seed trap, effective at capturing many types of small, light seeds, will allow more efficient sampling of seed rain in some plant communities.

\section{Literature Cited}

Cook, R.E. 1980. The biology of seeds in the soil. Ch. 6 p. 107-129. In: Demography and evolution in plant populations, O.T. Solbrig, ed. Botanical Monographs Vol. 15, Univ. of California Press, Berkeley.

Rabinowitz, D., and J. Rapp. 1980. Seed rain in a North American tallgrass prairie. J. of Appl. Ecol. 17:793-802.

Reichman, O.J. 1984. Spatial and temporal variation of seed distributions in Sonoran Desert soils. J. of Biogeography 11:1-11.

Verkaar, H.J., A.J. Schenkeveld, and M.P. van de Klashorst. 1983. The ecology of short-lived forbs in chalk grasslands: dispersal of seeds. New Phytologist 95:335-344.

Werner, P.A. 1975. A seed trap for determining patterns of seed deposition in terrestrial plants. Can. J. Bot. 53:810-813.

\title{
RANGELAND HYDROLOGY
}

\author{
by Farrel A. Branson, Gerald F. Gifford, Kenneth G. Renard, and \\ Richard F. Hadley
}

Unique in its emphasis on the hydrology of rangelands, primarily arid and semiarid lands. RANGELAND HYDROLOGY provides a text for one aspect of range management where none has existed before. This expanded Second Edition presents in-depth information for those who must manage rangeland or respond to questions about the impacts of land use practices on hydrology.

Included in the new Second Edition are a chapter on modeling with approaches to predicting the effects of land use, and a chapter on the rapidly developing field of snow pack management.

The 352-pages include 197 illustrations, providing rapid access to an assembly of data found nowhere else and useful in the preparation of environmental impact statements. Extensive bibliographic material with each chapter and a subject matter index add to the useableness of the book.

Range scientists and managers, soil conservationists, hydrologists, agricultural engineers, land reclamation specialists, wildlife managers, graduate and undergraduate students and their professors, as well as all interested in the hydrology of arid lands will find RANGELAND HYDROLOGY a valuable addition to their libraries. (352 pages paper laminated cover $\$ 15.00$ US) 